\title{
A NOÇÃO DE HABITUS E A POSSIBILIDADE DO PESQUISADOR POLÍTICO EM ESTUDOS ORGANIZACIONAIS
}

Marcio Sá1

Em meados do século passado, logo após ter obtido sua agregação em filosofia, Pierre Bourdieu foi convocado para prestar serviço militar numa Argélia ainda colônia francesa. O pensamento social francês daquele tempo estava polarizado entre duas correntes antagônicas, de um lado o estruturalismo de expoentes como Lévi-Strauss e Althusser, do outro o existencialismo de Sartre.

Foi ao viver na tensão de uma guerra de libertação nacional que Bourdieu iniciou variadas experiências de pesquisas que se seguiram por décadas. Tais experiências, articuladas com história e filosofia das ciências de seu tempo, o levaram a se posicionar entre os opostos então hegemônicos, ser apontado como fundador de corrente própria e eleito titular da cadeira de sociologia do Collegè de France em $1981^{2}$.

Nas últimas três décadas, com a ampla tradução para o inglês e a seguinte "importação transatlântica" da sua teoria social para os Estados Unidos, "Bourdieu mudou definitivamente seu status intelectual para se tornar um cientista social verdadeiramente dominante, provavelmente, o sociólogo mais influente no mundo nestes primeiros anos do novo milênio" (SANTORO, 2008, p. 3).

Quando se deu sua inesperada morte em janeiro de 2002, ele já era apontado como autor significativamente mais citado que outros notáveis como Habermas, Goffman e Giddens. No mesmo levantamento estatístico, é possível observar que a distância dele para os demais seguiu em crescimento vertiginoso ao menos até 2007 (SANTORO, 2008, p. 4).

Mas o que estaria contido em sua obra para levá-la a alcançar tamanho reconhecimento? Para muitos, sua mais distintiva originalidade pode ser encontrada quando se desloca o foco dos resultados dos seus estudos para a evolução e consolidação do seu modo próprio de trabalho,

\footnotetext{
${ }^{1}$ Professor da UFPE (Universidade Federal de Pernambuco), e-mail: marciodesa@gmail.com. Texto originalmente proferido no IV CBEO, na mesa redonda "Habitus, antes que método, de um pesquisador político", realizada em 20.10.2016, na Escola de Administração da UFRGS, Porto Alegre.

${ }^{2}$ Algumas destas e outras informações relevantes da trajetória de Pierre Bourdieu podem ser acessadas na "Cronologia de vida e obra" que consta na edição brasileira de Bourdieu (2005).

Revista Brasileira de Estudos Organizacionais - v. 3. n. 2, p. 197-203, dez.2016, eISSN: 2447-4851 Doi 10.21583/2447-4851.rbeo.2016.v3n2.89 Sociedade Brasileira de Estudos Organizacionais
} 


\section{A NOÇÃO DE HABITUS E A POSSIBILIDADE \\ DO PESQUISADOR POLÍTICO EM ESTUDOS ORGANIZACIONAIS \\ Marcio Sá}

ou seja, para seu habitus científico (cf. WACQUANT, 1992; SANTORO, 2011; SÁ, 2015a; SÁ, 2015b).

O próprio Bourdieu (1989a, p. 21-22) explicitou o que teria de ser ensinado sobre seu ofício, para ele, "essencialmente, um modus operandi, um modo de produção científico [...] cuja única maneira de o adquirir é o de ver operar praticamente ou observar o modo como este habitus científico - é bem este o seu nome -, sem necessariamente se tornar explícito em preceitos formais, 'reage' perante opções práticas".

O habitus científico é uma regra feita homem ou, melhor, um modus operandi científico que funciona em estado prático segundo as normas da ciência sem ter estas normas na sua origem: é esta espécie de sentido do jogo científico que faz com que se faça o que é preciso fazer no momento próprio, sem ter havido necessidade de tematizar o que havia que fazer, e menos ainda a regra que permite gerar a conduta adequada (BOURDIEU, 1989a, p. 23) .

Vale ainda reiterar aqui que após coletar diversas designações e usos do termo habitus nos trabalhos de Bourdieu, Rogers Brubaker (1993, p. 217, grifos meus em itálico) entendeu que ele "não estava definindo, mas sim caracterizando o conceito de diferentes modos para comunicar uma certa atitude ou postura teórica, de designar - e inculcar - um certo modo de olhar para o mundo".

Ao por tal trajetória sob o crivo da sua própria perspectiva sociológica em Esboço de auto-análise, Bourdieu (2005, p. 38, grifos meus em itálico) declarou que:

\footnotetext{
todos os momentos de minha história, em particular os diferentes partidos assumidos em matéria de pesquisa, podem parecer ajustados à sua necessidade sociológica, ou melhor, justificados neste registro, portanto, como se fossem muito mais racionais, ou então, mais raciocinados ou mais razoáveis do que de fato o foram, um pouco como se tivessem saído de um projeto consciente de si desde o começo. Ora, eu sei, e não farei nada para escondê-lo, que na realidade fui descobrindo aos poucos os princípios que guiavam minha prática, mesmo no terreno da pesquisa.
}

Este olhar retrospectivo nos permite pensar que a noção de habitus surgiu, também, como um instrumento epistêmico capaz de explicitar princípios de práticas incorporadas por ele mesmo, enquanto enfrentava os desafios do ofício. Teria tal noção serventia para inspirar uma postura politizada de pesquisa em nosso contexto? Antes e para melhor me colocar 


\section{A NOÇÃO DE HABITUS E A POSSIBILIDADE \\ DO PESQUISADOR POLÍTICO EM ESTUDOS ORGANIZACIONAIS \\ Marcio Sá}

perante esta e outras questões a serem aqui debatidas, preciso recuperar os dois pontos seguintes.

\section{Primeiro ponto: Os desejos de seu autor}

Uma forma que penso ser pertinente de resgatar a reflexão madura de Bourdieu sobre a origem e o uso deste seu conceito capital, então chamado por ele de "noção", é recuperar suas próprias palavras em $A$ gênese dos conceitos de habitus e de campo. Afinal, neste texto ele se debruça sobre a emergência do termo em sua trajetória ${ }^{3}$.

Desejoso de romper com o estruturalismo - afinal, ele próprio fez questão de registrar que para classificá-lo como estruturalista, "é preciso estar mal-intencionado, ou apenas mal-informado" (BOURDIEU, 2005, p. 103-4) -, mas ao mesmo tempo sem querer aderir ao existencialismo ou mesmo à economia clássica e seu homo economicus, Bourdieu (1989b, p. 60, grifos meus em itálico) dispensa fazer a genealogia dos conceitos alegando que estes não "nasceram de uma partenogênese teórica", logo, "não ganham muito em serem re-situados em relação aos usos anteriores". No seu caso, tendo emergido ao longo de uma prática científica reflexiva, estes assumem "por função, sobretudo, designar de maneira estenográfica, uma postura teórica, princípio de opções metódicas, tanto negativas como positivas, na condução da pesquisa. Neste sentido, por exemplo, a noção de habitus exprime sobretudo a recusa a toda uma série de alternativas nas quais a ciência social se encerrou".

Não tendo sido produzido por um "cálculo teórico" e sim fruto de "uma estratégia prática do habitus científico", ou seja, "espécie de sentido do jogo que não tem necessidade de raciocinar para se orientar e se situar de maneira racional no espaço", quando introduziu a noção Bourdieu também desejava "pôr em evidência as capacidades 'criadoras', ativas, inventivas, do habitus e do agente (que a palavra hábito não diz), [...] o habitus, como indica a palavra, é um conhecimento adquirido [...], indica a disposição incorporada, quase postural" (BOURDIEU, 1989b, p. 61).

Aos seus olhos, os primeiros usos da noção feitos por ele traziam um tanto disso de modo implícito, ou seja, uma "intenção teórica" que o aproximava dos utilizadores anteriores do termo e permitia "sair da filosofia da consciência sem anular o agente na sua verdade de operador prático de construção de objeto" (BOURDIEU, 1989b, p. 61-2).

Para Derek Robbins (2000, p. 26-7, grifos meus em itálico), este texto traz um "indicativo da insistência estratégica de Bourdieu de que ambos, $a$ sua carreira e seus conceitos, são misturas não intencionais de estratégia e

\footnotetext{
${ }^{3}$ Para maiores aprofundamentos neste ponto ver Sá (2015a, p. 44-61).
} 


\section{A NOÇÃO DE HABITUS E A POSSIBILIDADE \\ DO PESQUISADOR POLÍTICO EM ESTUDOS ORGANIZACIONAIS \\ Marcio Sá}

contingência", ou seja, "quando Bourdieu começou a usar o conceito de habitus, ele estava procurando por um conceito com o qual pudesse descrever ações estratégicas localizadas". Tal potencial descritivo seria útil não somente no âmbito da construção dos seus objetos de pesquisa, mas também para analisar sociologicamente ele próprio. Deste modo, também poderia servir para compreender tanto sua prática de pesquisa quanto como se deram suas tomadas de posições no campo científico francês.

Em termos epistêmicos, a noção de habitus científico é o instrumento elaborado e desenvolvido por Bourdieu ao longo da evolução reflexiva e da explicitação dos princípios práticos do ofício tal qual o desempenhava. Os efeitos da mistura de estratégia e contingência na carreira e na elaboração de seus conceitos, assim como o potencial da ideia de habitus para orientar a descrição de "ações estratégicas localizadas" são dois aspectos importantes de serem retidos aqui.

\section{Segundo ponto: Bourdieu e nossa compreensão incorporada do ofício, contra a ilusão lógica de puro método}

Como o pensamento metodológico de Pierre Bourdieu é o foco teórico desta mesa redonda, para avançar neste ponto, me voltarei para um tópico específico de Science de la Science et Refléxivitét intitulado "O ofício de cientista".

Bourdieu (2014, p. 58-9) atribui ao formalismo, residente numa visão escolástica da prática científica, a elaboração de "uma espécie de ficção". Esta leva a lógica do método a se sobrepor ao relato do que efetivamente se faz no curso da pesquisa e "impede que se conheça e se reconheça a verdade da prática científica como produto de um habitus científico, de um sentido prático (de tipo muito particular)". Contra o que chama de "epistemologia logicista", propõe que: "reintroduzir a ideia de habitus remete as práticas científicas, não para o princípio de uma consciência cognitiva que age de acordo com as normas explícitas da lógica e do método experimental, mas para a ideia de 'ofício', ou seja, um sentido prático dos problemas a tratar, das maneiras adaptadas para o tratar, etc".

A força entre nós da ilusão de que a lógica do método pode ser implementada de modo asséptico, também pode nos impedir de observar que

uma prática científica possui todas as características reconhecidas às atividades mais tipicamente práticas, como as

\footnotetext{
${ }^{4}$ Livro que teve origem no último curso que ofereceu no Collège de France em 2001. Sua edição portuguesa publicada sob o título de "Para uma sociologia da ciência" (Bourdieu, 2014).
} 


\title{
A NOÇÃO DE HABITUS E A POSSIBILIDADE \\ DO PESQUISADOR POLÍTICO EM ESTUDOS ORGANIZACIONAIS \\ Marcio Sá
}

atividades desportivas ou artísticas. Mas tal não impede que seja também, sem dúvida, a forma suprema de inteligência teórica: [...] é 'uma consciência teórica realizada', ou seja, incorporada, no estado prático. [...] A especificidade do 'ofício' do cientista decorre do fato de essa aprendizagem ser a aquisição de estruturas teóricas extremamente complexas que podem, além disso, ser colocadas em fórmulas, especialmente matemáticas, e que se podem adquirir de maneira acelerada graças à formalização (BOURDIEU 2014, p. 61).

É válido ainda registrar que, Bourdieu recorreu e fez uso estratégico dos mais diversos recursos metodológicos então disponíveis em sua prática, em função de cada um dos objetos de pesquisa que construiu e abraçou, inclusive mesclando-os com originalidade. Entretanto, tal pluralismo metodológico se dava sob o comando uma "compreensão incorporada" (TAYLOR, 2000) do ofício, decisiva ao modo como tais recursos são utilizados.

Em sintonia com isso está seu modo de observar teoria e metodologia como indissociáveis. Conviç̧ão praticada nos estudos que conduziu, suas elaborações teóricas emergiram de desafios que lhe foram apresentados em situações de pesquisa nas quais sentiu a necessidade de ressignificações conceituais, como a do próprio conceito de habitus.

Bourdieu (2014, p. 62-3) reconhece ser tal relação entre a prática e o método,

\begin{abstract}
uma forma particular da questão wittgensteiniana de saber o que significa o fato de 'seguir uma regra'. Não se age de acordo com um método, tal como não se segue uma regra, por um ato psicológico de adesão consciente, mas essencialmente deixando-se levar por um sentido do jogo científico tanto com as suas regularidades como com as suas regras. [...] [Pensemos nas] regras que regem a apresentação de textos científicos, por exemplo. [...] Em suma, as normas só os condicionam porque eles se propõem a cumpri-las por um ato de conhecimento e reconhecimento prático que lhes confere eficácia, por outras palavras, porque estão dispostos (ao fim de um trabalho de socialização específica).
\end{abstract}

Há uma nuance importante a ser destacada aqui: está nas disposições dos agentes e não na própria regra, a sua maior possibilidade de "cumprimento". Deste segundo ponto é importante reter a ideia de compreensão incorporada, afinal, ela gera o sentido prático que orienta a ação também neste nosso ofício.

\section{Ponto para debate: A possibilidade de um sentido prático-político compartilhado entre pesquisadores em Estudos Organizacionais}




\title{
A NOÇÃO DE HABITUS E A POSSIBILIDADE \\ DO PESQUISADOR POLÍTICO EM ESTUDOS ORGANIZACIONAIS \\ Marcio Sá
}

Se para Taylor (2000), “grande parte da ação humana só ocorre na medida em que o agente se compreende como parte integrante de um 'nós' e como tal se constitui a si mesmo", tal compreensão individual e coletiva também pode servir de base para "novas articulações". Por exemplo, no modo de exercer um ofício que prevalece numa comunidade científica, uma vez que neste atuamos por meio de "compreensões incorporadas" ambientadas na coletividade da qual tomamos parte (TAYLOR, 2000).

O habitus científico, segundo Bourdieu (2014, p. 63),

\begin{abstract}
assume formas específicas segundo as especialidades: [...] os contatos entre ciências, que, tal como os contatos entre civilizações, possibilitam a explicitação das disposições implícitas, especialmente nos grupos interdisciplinares que se constituem em redor de um novo objeto, poderiam ser um terreno privilegiado de observação e objetivação destes esquemas práticos". Numa comunidade interdisciplinar e em formação como esta, reside uma possibilidade ímpar de observar e objetivar tais esquemas práticos sendo engendrados.
\end{abstract}

“Os efeitos da mistura de estratégia e contingência na carreira e na elaboração de seus conceitos", assim como o potencial da ideia de habitus para orientar a descrição de "ações estratégicas localizadas", retidos dos pontos anteriores, quando conjugados com as possibilidades de novas articulações abertas a partir de uma compreensão incorporada em termos individuais e sociais, compõem as ideias força que me permitem pensar na possibilidade-título desta exposição. Afinal, é possível avançar neste sentido político como constitutivo do pesquisador em Estudos Organizacionais?

Nossa questão-desafio é a do plano de continuidade que passaria a acontecer, pelo habitus, entre o processo prático da pesquisa e contexto circunstancial do pesquisador, sem prejuízo das regras de trabalho rigoroso aceitas pela comunidade científica e na direção da situação "sócio-histórica-assumida" do pesquisador, um pesquisador indissociado das questões de sua polis, ou seja, um pesquisador político.

\section{Referências}

BOURDIEU, P. Introdução a uma sociologia reflexiva. In: BOURDIEU, P. Poder simbólico. Portugal/Brasil: Difel/Bertrand, 1989a, p. 17-58.

BOURDIEU, P. A gênese dos conceitos de habitus e campo In: BOURDIEU, P. Poder simbólico. Portugal/Brasil: Difel/Bertrand, 1989b, p. 59-73.

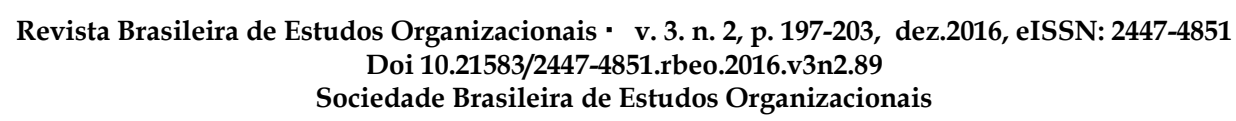




\section{A NOÇÃO DE HABITUS E A POSSIBILIDADE \\ DO PESQUISADOR POLÍTICO EM ESTUDOS ORGANIZACIONAIS \\ Marcio Sá}

BRUBAKER, R. Social theory as habitus. In: CALHOUN, C. et al. (Orgs.). Bourdieu: Critical perspectives. Cambridge: Polity Press, 1993, p. 212-234.

ROBBINS, D. The socio-genesis of the thinking instruments. In: ROBBINS, D. Bourdieu and culture. Londres: Sage, 200, p. 25-41.

BOURDIEU, P. Esboço de auto-análise. São Paulo: Companhia das Letras, 2005.

BOURDIEU, P. Por uma sociologia da ciência. Lisboa: Edições 70, 2014 [2001]. [Science de la science et refléxivité]

SÁ, M. Os filhos das feiras e o campo de negócios agreste. Tese de Doutoramento em Sociologia. 2015. 271f. Braga: Universidade do Minho, 2015a. Disponível em: http://repositorium.sdum.uminho.pt/handle/1822/35680. Acesso em: 24 jul.2015.

SÁ, M. Construtivismo bourdieusiano como linguagem: uma interpretação pragmática. Configurações, Braga: Cics-Univ. do Minho, 2015b, n. 16, p. 115-128. Disponível em: http://configuracoes.revues.org/2881. Acesso em: 29 abr.2015.

SANTORO, M. Putting Bourdieu in the Global Field (Introduction to the Symposium The International Circulation of Sociological Ideas: The Case of Pierre Bourdieu). Sociologica, Bologna: Società editrice il Mulino, 2008, n. 2, p. 1-32.

SANTORO, M. From Bourdieu to cultural sociology. Cultural Sociology, v. 5, n. 1, p. 3-23, 2011.

TAYLOR, C. Seguir uma regra. In: Argumentos filosóficos. São Paulo: Edições Loyola, (2000 [1995]), p. 181-196. [Philosophical Arguments]

WACQUANT, L. Preface. In: BOURDIEU, P; WACQUANT, L. (orgs.), An Invitation to Reflexive Sociology. Chicago: The University of Chicago Press, 1992, p. ix-xiv.

Submetido em: 24/03/2017

Aprovado em: 20/04/2017 